\title{
Meningkatkan Sains Permulaan untuk Anak Usia Dini dengan
}

Pemanfaatan Media Herbarium

R. F. Imran ${ }^{1, a)}$; R. Partikasari' ${ }^{1}$; I. S. Jahniar ${ }^{1)}$

\section{Affiliation:}

1. Program Studi Pendidikan Guru PAUD FKIP UNIVED

Bengkulu

Corresponding Author:

a.rannyimran@gmail.com

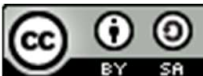

Abstract

This research was conducted in RA Babul Jannah Bengkulu City. This study conducted a qualitative descriptive study. Data collection techniques used are observation, interviews, and documentation. The purpose of this study is to develop science for early childhood by using herbarium media at 5-6 years old in RA Babul Jannah Bengkulu City. Based on the results of this study it can be concluded that early childhood science through herbarium media in RA Babul Jannah Bengkulu City increased, with categories starting to develop (MB) there were 3 children with a percentage rate of $25 \%$, the category developed according to expectations $(B S H)$ there were 3 children with a percentage rate of $25 \%$, including the category of developing very well (BSB) there are 9 children with a percentage rate of $50 \%$.

Keyword: Science for early childhood, media use, herbarium media 


\section{Pendahuluan}

Pengembangan sains permulaan akan membuat peserta didik menjadi lebih aktif untuk berinteraksi dengan lingkungan sekitarnya. Menurut Ade Utami, dkk (2013:522), sains merupakan pengetahuan yang diperoleh melalui pembelajaran dan pembuktian atau pengetahuan yang melingkupi suatu kebenaran umum dari hukum-hukum alam yang terjadi misalnya didapat dan dibuktikan melalui metode ilmiah.

Menurut Slamet Suyanto (2005:83), sains dapat melatih anak untuk menggunakan kemampuan panca indra, melatih menghubungkan sebab akibat, mengajarkan anak untuk menggunakan alat ukur, melatih anak untuk menemukan dan memahami peristiwa serta memahami konsep-konsep benda.

Dalam pembelajaran sains agar dapat menarik perhatian anak seorang guru dapat menggunakan media sehingga anak dapat belajar dengan lebih menyenangkan. Media merupakan alat bantu bagi guru dalam proses pembelajaran, namun media dapat menjadi penghambat jika pengunanya tidak sesuai dengan esensi tujuan yang telah dirumuskan. Penggunaan media pembelajaran yang sesuai dapat membuat proses pembelajaran menjadi lebih variatif, interaktif, dan menyenangkan.

Media merupakan alat yang sangat membantu dalam proses belajar mengajar terutama di Taman Kanak-kanak. Dengan adanya media dapat mempermudah guru dalam menyampaikan materi ajar kepada anak didiknya. Pentingny 1 a dalam belajar mengajar adalah dapat $m$ a dan membangkitkan rasa senang dan gembira bagi anak-anak dan memperbarui semangat mereka untuk memantapkan pengetahuan pada anak-anak serta menghidupkan suasana kegiatan pembelajaran. Adapun fungsi media adalah perangsang dan alat yang disediakan guru untuk mendorong anak belajar cepat dan merupakan alat bantu pendengar dan penglihatan bagi peserta didik dalam rangka memperoleh pengalaman yang signifikan.

Berdasarkan hasil observasi awal, media yang digunakan oleh guru RA Babul Jannah masih menggunakan papan tulis untuk memberikan contoh dalam pembelajaaran sains. Pembelajaran sains di RA tersebut yaitu dalam kegiatan mencampur warna. Misalnya warna biru dicampur dengan warna merah menjadi warna ungu. Masih banyak tema yang dapat digunakan dalam pembelajaran sains seperti: a). diri sendiri, b). lingkungan, c). kebutuhanku, d). binatang, e). tanaman, f). rekreasi, g). pekerjaan, h). air, udara dan api, i). Alat komunikasi, j). tanah airku, k). alam semesta.

Salah satu upaya yang dapat mengembangkan kemampuan sains permulaan dalam pembelajaran yaitu dengan menggunakan media herbarium seperti tanaman obat-obatan (kembang sepatu, kumis kucing, daun sirih, daun jambu biji, kunyit). Herbarium merupakan koleksi spesimen yang telah dikeringkan/diawetkan biasanya disusun berdasarkan sistem klasifikasi. Herbarium kering adalah koleksi spesimen yang telah dipres dan dikeringkan, serta ditempel pada kertas (mounting paper), diberi label berisi keterangan yang penting dan sulit dikenali secara langsung dari spesimen kering tersebut, diawetkan serta disimpan dengan baik ditempat penyimpanan yang telah disediakan. Herbarium sebagai suatu koleksi spesimen tumbuhan yang diawetkan dapat digunaan sebagai suatu media pembelajaran sangat diperlukan dalam proses pembelajaran biologi. (Purwanti, 2012:80). Kelebihan herbarium, yaitu pengguna praktis dan ekonomis, dapat dibawa kemana saja, baik dikelas maupun di laboratorium.

Berdasarkan latar belakang di atas, maka peneliti mengangkat judul yaitu: "Meningkatkan Sains untuk Anak Usia Dini dengan Pemanfaatan Media Herbarium."

\section{Metode Penelitian}

1. Metode penelitian

Dalam metode penelitian ini penulis menggunakan metode penelitian deskriptif kualitatif. Menurut (Sugiyono, 2018:56) penelitian kualitatif bertujuan memahami subjek penelitiannya secara mendalam dan bersifat interpretatif, artinya mencari dan menemukan makna. Sifat penelitian ini adalah deskriptif kualitatif yaitu penelitian yang bertujuan menggambarkan secara sistematis mengenai fakta-fakta yang ditemukan dilapangan, bersifat verbal, kalimat fenomena-fenomena, dan tidak berupa angka-angka. Deskriptif digunakan untuk menemukan prinsip-prinsip dan penjelasaan yang mengarah pada kesimpulan.

\section{Prosedur penelitian}

a. Observasi Awal

Sebelum membuat proposal penelitian suatu objek, seorang peneliti harus melakukan observasi awal. Dalam penelitan yang akan dilakukan ini, 
peneliti telah melakukan observasi awal di sekolah yang dituju. Dalam observasi awal inipeneliti menemukan beberapa masalah berkenaan dengan judul penelitian yang hendak peneliti lakukan sekarang ini. Masalah yang peneliti temui pada saat melakukan observasi awal di sekolah tersebut yaitu mesngenai media tentang sains. Observasi digunakan untuk mengamati tentang pengaruh metode media herbarium dengan tema tanaman terhadap konsep pembelajaran yang dapat anak kuasai. Kegiatan observasi dilaksanakan dengan tujuan untuk memperoleh data yang berhubungan dengan penguasaan konsep anak usia dini. Data hasil observasi dapat memberikan informasi mengenai penguasaan konsep sains yaitu dalam hal mengobservasi, mengklasifikasi, meramalkan, serta mengkomunikasikan berbagai informasi yang dapat diserap oleh siswa.

b. Media herbarium dengan tema tanaman

Herbarium merupakan koleksi spesimen yang telah dikeringkan biasanya disusun berdasarkan sistem klasifikasi. Dalam hal ini herbarium yang digunakan yaitu herbarium kering. Berikut ini adalah langkag-langkah pembuatan herbarium menurut Maya (2017:80-81)

\section{Alat dan bahan}

c. Pisau/cutter Gunting

d. Selotip

e. Kertas koran

f. Kayu balok

g. Koran

h. Benang dan jarum

i. Tanaman kembang sepatu (Hibiscus rosasinensis $L$ ).

Langkah-langkah pengeringan:

a. Bersikan tanaman dari debu dan kotoran, kemudian susun bunga serta daun bersama tangakai tumbuhan di selembaran kertas koran.

b. Gunting sedikit selotip kertas untuk menguatkan bagian tangkai atau ranting. Tanpa selotip, tangkai akan mudah bergeser.

c. Pasang selotin dengan sisi kiri dan kanan merekat di koran. Lakukan hal yang sama di beberapa permukaan tangkai agar letak tumbuhan tidak berubah atau bergeser.

d. Lipat koran hingga seluruh bagian tumbuhan tertutup sempurna. Setelah itu baru bisa melakukan pengepresan.
Cara penyusunan herbarium:

a. Setelah kering, letakkan spesimen lalu atur di atas kertas, oleskan lem di semua bagian daun hingga merata.

b. Rekatkan spesimen di atas kertas. Letakkan pemberat sementara di atas kertasnya selama kurang lebih 15 menit, hingga lem mengering.

c. Setelah mengering tusuk kertas di dekat ranting dari bawah ke atas, lalu tarik jarum dari atas kertas sampai benang di bagian bawah hanya tersisa sedikit.

d. Tusukkan jarum ke bawah hingga menembus kertas, lalu tarik sampai benang terlihat menjepit ranting. Kemudian ikat tali di ujung kertas.

e. Kemudian lem plastik di atas kertas yang ditempeli daun, ranting dan bunga. Gunakan balok untuk menguatkan lem dan meratakan spesimen.

f. Herbarium siap untuk di jadikan media pembelajaran.

4. Penggunaan media herbarium di RA Babul Jannah

j. Membuat RPPH tema tanaman

k. Membawa herbarium di kelas sebagai media pembelajaran

1. Mengamati bentuk media herbarium

m. Mengenali jenis tanaman yang telah dibuat menjadi media herbarium.

5. Kehadiran Penelitian

Penelitian bertindak sebagai instrumen sekaligus sebagai pengumpul data serta peneliti juga sebagai pengamat langsung metode observasi, wawancara, dokumentasi, dan sebagai pengumpul dokumen untuk penelitian.

6. Data dan Sumber Data

Data didapat dari penelitian ini adalah observasi, wawancara dan dokumentasi.

7. Teknik Pengumpulan Data dan Instrumen Penelitian

n. Observasi

Menurut Sugiyono (2013:145) observasi merupakan suatu proses kompleks. Suatu proses yang tersusun dari berbagai biologis dan psikologis, dua di antaranya yang tepenting adalah proses-proses pengamatan dan ingatan. 


\section{o. Wawancara}

Menurut Estreberg dalam sugiyono (2013:231) merupakan pertemuan antara dua orang untuk bertukar informasi dan ide melalui tanya jawab, sehingga dapat dikontruksikan makna dalam satu topik tertentu.

p. Dokumentasi

Menurut sugiyono (2013:354) dokumentasi merupakan catatan peristiwa yang sudah berlalu.

\section{Teknik Analisis Data}

Analisis data dalam penelitian ini dilakukan melalui reduksi data. Reduksi data adalah proses analisis data yang dilakukan untuk mereduksi dan merangkum hasil-hasil penelitian dengan menitikberatkan pada hal-hal yang dianggap penting oleh peneliti. Reduksi data bertujuan untuk mempermudah pemahaman terhadap data yang telah terkumpul sehingga data yang direduksi memberikan gambaran lebih rinci (Sugiono 2015:80).

\section{Hasil Penelitian dan Pembahasan}

Pembelajaran sains yang sudah dilaksanakan di RA sudah cukup baik, akan tetapi media pembelajaran yang dijadikan bahan alam masih belum banyak digunakan. Agar dapat digunakan sebagai media pembelajaran yang dapat digunakan dalam waktu yang lama diperlukan Media Herbarium. Spesimen herbarium adalah tanaman yang sering dijumpai orang atau anak disekitar mereka.

Berdasarkan penelitian yang telah dilakukan dikelompok B2 RA Babul Jannah yang terletak di jalan beringin 2 No 21 Rt 05 Rw 01 kelurahan padang jati Kecamatan Ratu Samban Kota Bengkulu yang berjumlah 15 orang anak penelitian ini akan mengambil tema yaitu tema tanaman. Penelitian dalam pelaksanaan pembelajaran dilakukan persiapan pembelajaran yaitu:

1. Membuat rencana pelaksanaan (RPPH)

2. Menyiapkan media pembelajaran yaitu media herbarium dari tanaman obat

3. Menyiapkan lembar observasi dan wawancara

4. Dokumentasi

Aspek yang diamati adalah ketika anak mengamati media dan menyuruh anak menulis dibuku tulis dengan kata herbarium. Terlihat anak masih malas dalam belajar dan masih ada yang mengeluh capek. Anak kurang tertarik dalam menuliskan kata yang diucapkan atau disebutkan oleh peneliti.

Pada hari berikutnya yang diamati adalah ketika anak mengamati media seperti mengenal warna bunga, warna daun, bentuk daun, dan juga kegunaan masing-masing dari tanaman yang sudah dibuat menjadi media herbarium. Pada saat kegiatan berlangsung ada beberapa anak yang terlihat kemampuan sainsnya mulai berkembang.

Pada hari berikutnya ada beberapa anak yang kemampuan sainsnya mulai meningkat serta banyak anak yang berkembang sesuai harapan, dan di hari selanjutnya sudah banyak anak yang kemampuan sainsnya mulai berkembang dan terlihat dari konsentrasi anak, daya fikir dan daya ingat anak pada pembelajaran herbarium dari tanaman obat yang ada disekitar anak sesuai harapan dan ada pula yang berkembang sangat baik. Berikut hasil penilaian dari hari pertama samapai hari terahir saat proses pembelajaran:

Berdasarkan data hasil penelitian pembelajaran awal dikemukakan bahwa, persentase anak tidak ada satu pun anak yang mendapatkan bintang 3 dan bintang 4 . Persentase anak yang mendapat nilai bintang satu sebanyak 11 orang anak $(73.33 \%)$, bintang 2 sebanyak 4 orang anak (26.67\%). Berdasarkan data diatas diketahui bahwa perhitungan pengembangan sains permulaan anak pada pembelajaran pertama belum berkembang.

Berdasarkan data hasil penelitian dikemukakan bahwa, masih belum ada anak yang mendapat bintang 3 dan bintang 4 . Persentase anak yang mendapatkan nilai bintang satu 5 orang anak $(33,33 \%)$. Persentase anak yang mendapat nilai bintang dua sebanyak 8 orang anak $(53,33 \%)$. Berdasarkan data diatas perkembangan permulaan sains anak mulai berkembang, Terlihat dari tabel diatas anak yang mulai berkembang sebanyak 6 orang anak, karena anak menggambar dan mewarnai tetapi dalam mewarnai anak belum mewarnai secara menyeluruh.

Berdasarkan data hasil penelitian dikemukakan bahwa, masih belum ada anak yang mendapat bintang 3 dan bintang 4. Persentase anak yang mendapatkan nilai bintang satu 5 orang anak $(33,33 \%)$. Persentase anak yang mendapat nilai bintang dua sebanyak 8 orang anak $(53,33 \%)$. Berdasarkan data diatas perkembangan permulaan sains anak berkembang sesuai harapan, karena anak membuat kolase sesuai warna tetapi tidak menyeluruh (setengah). 
Presentase anak yang mendapat bintang dua 3 orang anak (20\%). Persentase anak yang mendapatkan nilai bintang tiga 3 orang anak $(20 \%)$. Persentase anak yang mendapat nilai bintang empat sebanyak 9 orang anak $(60 \%)$. Berdasarkan data diatas perkembangan permulaan sains anak sudah berkembang sanagat baik, dilihat dari tabel diatas anak-anak sudah bisa menyusun spesimen herbarium sesuai dengan media yang sudah ada.

Berdasarkan uraian perhitungan pada tabel diatas adalah pengembangan kemampuan sains permulaan anak dapat dikatakan berkembang atau sudah baik dengan menggunakan media herbarium, karena perkembangan sains permulaan anak sebagai suatu pengetahuan yang diperoleh dengan menggunakan metode-metode yang berdasarkan pada pengamatan dengan penuh penelitian. Pada pembelajaran sains permulaan ini anak mampu menguasai atau memahami tentang media herbarium dari anak yang belum tahu bentuk, warna-warna bunga, dan kegunaan sekarang anak sudah tahu memahami lewat media herbarium.

Perkembangan sains permulaan melalui media herbarium pada anak yang merupakan salah satu cara dalam mengasah daya fikir pada anak yang bertujuan agar meningkatkan perkembangan anak. Seperti pembelajaran sains permulaan anak melalui media herbarium salah satunya untuk menciptakan keberhasilan pada anak terutama di Ra Babul Jannah Kota Bengkulu, seperti:

1. Mengamati bentuk daun dan batang

2. Mengamati warna daun

3. Mengamati warna bunga

4. Mengenal apa saja tanaman obat

5. Kegunaan tanaman obat

Berdasarkan hasil penelitian di RA Babul jannah anak-anak masuk jam 07.30 WIB mengajak anak-anak berbaris dan bernyanyi didepan aula disertakan dengan membacakan rukun islam, rukun iman, sifat-sifat rasul, berhitung bahasa arab dan bahasa inggris 1-10, berhitung mundur, niat berwudhu, doa sesudah berwudhu dan terahir membacakan asmaul husna disertakan salam dengan guru-guru dan masuk aula. Ketika di dalam aula anak-anak sholat dhuha bersama dengan dituntun guru yang piket pada hari itu. Setelah solat dhuha selesai anak-anak membacakan surat pendek dan juga hadis yang sudah ditentukan guru. kemudian anak-anak masuk kelas membuka buku baca dan membaca satu per satu anak membaca kedepan. Pada kegiatan awal yaitu menjelaskan hari apa, tanggal berapa, tahun berapa dan menjelaskan tema dan sub tema. Kemudia kegiatan yang akan dilakukan adalah:

1. Menyiapkan media sesuai dengan materi yaitu dengan menggunakan media herbarium dari tanaman obat. Sebelum melakukan kegiatan peneliti menunjukkan media dan menanyakan kepada anak-anak apa nama media yang peneliti buat, terdapat tanaman apa sajakah pada media herbarium yang peneliti buat, anak-anak berlombalomba menjawab pertanyaan peneliti dan peneliti memanggil salah per satu anak untuk maju kedapan kelas dan menjawab pertanyaan yang sudah diberikan.

2. Selanjutnya peneliti menjelaskan fungsi dan kegunaan dari tanaman obat yang peneliti buat menjadi media herbarium tersebut. Kemudian anak-anak disuruh duduk yang rapi dan menanyakan bentukbentuk daun, warna daun, warna bunga dan warna batang dari media herbarium yang sudah disiapkan, anak-anak pun berlombalomba menjawab dan peneliti menunjukan satu per satu anak agar bisa menjawab.

3. Kegiatan selanjutnya peneliti menjelaskan tentang herbarium, apa itu herbarium dan bagaimana cara pembuatan herbarium. Anak-anak disuruh satu per satu mengamati media yang sudah peneliti buat menjadi herbarium (melihat dan meraba). Setelah anak-anak selesai mengamati media selanjutnya menanyakan kepada anak-anak bagaimana bentuk dari masing-masing daun, bunga, warna bunga dan daun, bentuk batang dan warna batang. Anak-anak dengan semangatnya menjawab pertanyaan dan berlomba-lomba menjawab.

4. Setelah itu peneliti mengajak anak-anak menyanyikan lagu sesuai dengan tema yaitu tentang tanaman, anak-anak disuruh berdiri dan beryanyi bersama-sama, hal ini agar anak-anaik tidak merasa bosan ketika berada didalam kelas.

5. Kegiatan berikutnya istirahat sekaligus menunggu waktu pulang anak-anak disuruh tidur siang, setelah tidur siang anak-anak mengambil wudhu kemudian sholat zuhur dan setelah selesai disertai zikir dan doa. Kemudian anak-anak membereskan alat sholat dan duduk yang rapi kembali. 
6. Kegiatan selanjutnya menanyakan kembali apa pelajaran hari ini, menanyakan kembali perasaan anak pada saat belajar herbarium, kemudian anak-anak membacakan surat pendek seperti, annas, alfalaq, al-ikhlas dan disertai juga dengan membaca do'a selesai belajar, do'a naik kendaraan, do'a keluar kelas, do'a masuk rumah. Setelah selesai membaca do'a-do'a dilanjutkan dengan janji pulang sekolah kemudian keluar kelas sambil menunggu jemputan orang tua dan salaman.

Pengembangan kemampuan sains permulaan anak dapat dikatakan berkembang atau sudah baik dengan menggunakan media herbarium, apabila anak sudah bisa menulis H-E-R-B-A-R-I-U-M, nama-nama tanaman obat sebagai media herbarium, mengetahui bentuk dari tanamantanaman obat, dapat membedakan bentuk daun tanaman obat dapat meniru warna gambar tanaman obat, dapat membuat kolase tanaman obat dengan menggunakan kertas origami, dan anak dapat menyusun spesimen menurut media yang sudah disiapkan.

Jadi hasil pengamatan peneliti dari hari pertama sampai akhir penelitian mengenai pengembangan sains permulaan di RA Babul Jannah sudah berkembang sangat baik.

\section{Kesimpulan}

Berdasarkan hasil penelitian yang dilakukan maka dapat penulis simpulkan bahwa pengembangan kemampuan sains permulaan anak usia dini melalui media herbarium kelompok B pada Ra Babul Jannah Kota Bengkulu media herbarium sudah berkembang sangat baik. Pembelajaran sains permulaan pada anak mampu menguasai atau memahami tentang media herbarium dari anak yang belum tahu bentuk, warna-warna bunga, dan kegunaan sekarang anak sudah tahu atau memahami lewat media herbarium. Pengembangkan pembelajaran sains anak usia dini ditunjukkan agar anak-anak memiliki kemampuan memecahkan masalah yang dihadapinya.

\section{Daftar Pustaka}

Achsin. 2010. Media Belajar, Jakarta: Rineka Cipta.

Afifah. 2014. Ilmu Pengetahuan Alam, Semarang: Universitas Semarang

Amien. 2010. Mengajarkan Ilmu Pengetahuan
Alam (IPA) dengan Menggunakan metode "Discovery dan inquiry". Jakarta: Depdikbud Dikti PPLPTK.

Asimov, Isaac. 1995. Use of the trerm in science ficition.

Badru Zaman, dkk. 2009. Media dan Sumber Belajar. Jakarta: Universitas Terbuka.

Brewer. 2007. Sains, Jakarta: Graha Ilmu.

Carin, dkk, RB. 2002. Teaching Scionce Though Discovy. Columbus: Merrill Publiching Company.

Conant, Fisher. 2003. Pembelajaran Sains. Jakarta: Penerbit Erlangga.

Dayton, Kemp, J.E. D.k. 2006. "Planning and Producing Instructional Media". Combridge: Harper \& How Publishers, New York.

Dawson. 2004. Sains, Jakarta: PT Gramedia Pustaka.

Djuharie, O. Setiawan. 2005. Panduan Membuat Karya Tulis. Bandung: CV. Yrama widya.

Ely, Gerlach. 1971. Teaching \& Media: A Systematic Approach. Second Edition, by V.S Gerlach \& D.P. Ely, 1980, Buston, MA: Allyn and Bacon. Copyright 1980 by Person Education.

Gerlach, dkk. 2006. Dasar-dasar Evaluasi Pendidikan, Jakarta: Bumi Aksa.

Iwan, 2014. Manfaat Media. Jakarta: FK Universitas Indonesia.

Klimer, dkk. 1995. Transpriming Science Curriculum. In s Bredekamp \& Rosegrant, T. (Eds). Reacihing Potentials: Tranforming Early Childhood Curriculum and Assessment, vol 2. Washington, DC : NAEYC, PP.43-63.

Leeper, E.M. 1994. Tujuan Pembelajaran Sains. Medan: Media Persada.

Maya. 2017. Seni Membuat Hebarium. Jakarta : PT Tiga Serangkai Pustaka Mandiri.

Miles, m.b \& A.M. 1992. Analisis Data Kualitatif. Terjemahan oleh Tjetjep Rohendi. 1992. Jakarta: Penerbit Universitas Indonesia.

Moleong, Lexy J. 2007. Metodologi Penelitian Kualitatif, Penerbit PT Remaja Rosdakarya Offset, Bandung.

Purwanti.

Herbarium.http://staff.uny.ac.id/sites/default/p endidikan/Purwanti $\%$

20Widhy\%20Hastuti,\%20S.Pd.,\%20M.Pd./12

th\%20herbarium.pdf, (On;ine) diakses 9 Februari 2018.

Rohan dkk. 2001. Pengelolahan Sumber Daya Alam. Jakarta: Gramedia.

Sugiyono. 2018. Metode Penelitian Kualitatif, 
kuantitatif, dan R \& D. Bandung: Alfabeta.

Susanto, Ahmad 2016. Teori Belajar dan Pembelajaran. Jakarta Prenada Media Group.

Sunarti. 2013. Prosedur Penelitian Suatu Pendekatan Praktik. Jakarta : Rineka Cipta.

Suyanto, Slamet. 2005. Dasar-dasar Anak Usia Dini. Yogyakarta: Hikayat Publishing.

Siyono S, Rohan HH. 2013. Buku Ajar Kesehatan Reproduksi. Yogyakarta: Nuha Medika.

Sumaji, Nana. 2007. Pendidikan Sains dan Humanistis. Yogyakarta: Kanisius.

Thoiruf, 2008. Menjadi Guru Inisiator. Semarang: Rasail.

Utami dkk, 2013. The miracle of Herbs. Jakarta: UMG press.

Van Steenis, C.G.G.J., 2003, Flora, diterjemahkan oleh Surjoeinoto, dkk, PT. Pradnya Paramita, Jakarta.

Wibowo. 2007. Manajemen Kinerja. Jakarta: PT. Raja Grafindo Parisada.

Yaumi dkk, 2013 kecerdasan Jamak. Jakarta: Kencana. 